
Veronese, M.V.;Guareschi, P. "Possibilidades solidárias e emancipatórias do trabalho: campo fértil para a prática da
Psicologia Social Crítica"

\title{
POSSIBILIDADES SOLIDÁRIAS E EMANCIPATÓRIAS DO TRABALHO: CAMPO FÉRTIL PARA A PRÁTICA DA PSICOLOGIA SOCIAL CRÍTICA
}

\author{
Marília Veríssimo Veronese \\ Universidade do Vale do Rio dos Sinos \\ Pedrinho Guareschi \\ Pontifícia Universidade Católica do Rio Grande do Sul
}

\begin{abstract}
RESUMO: O artigo discute a inserção da psicologia social crítica no campo da economia solidária, como um espaço laboral passível de constituir modos singularizados de trabalhar. Para tanto, revisa brevemente os principais conceitos referentes ao trabalho associativo e solidário, relacionando-o com as questões da subjetividade e da contemporaneidade. Questiona as referências emancipatórias das ciências sociais críticas, em especial a psicologia, colocando a necessidade de cartografar novos mapas para trilhar o "labirinto" da contemporaneidade, com suas ambigüidades e possibilidades, ao analisar um registro empírico tomado do campo do cooperativismo em bases solidárias. Finaliza colocando em pauta uma agenda progressista para a psicologia, quando inserida nessa realidade específica do mundo do trabalho.
\end{abstract}

Palavras-chave: Economia solidária, psicologia social, subjetividade.

\section{SOLIDARY AND EMANCIPATORY POSSIBILITIES OF LABOR: FERTILE FIELD FOR THE PRACTICE OF CRITICAL SOCIAL PSYCHOLOGY}

ABSTRACT: The paper discusses the insertion of critical social psychology in the field of solidary economy, as a laboral setting able to constitute singularized ways of working. For that, it briefly reviews the field of associative and cooperative labor, relating it with the issues of subjectivity and contemporaneity. It questions the emancipatory references of critical social sciences, specially psychology, raising the need of the cartography of new maps to outline the labyrinth of contemporaneity, with its ambiguities and possibilities, analyzing an empirical register taken by the field of cooperative system based on solidarity. Finally, it raises the need of a progressist agenda for psychology, when inserted in this specific reality of the labor world.

Key-words: Solidary economy, social psychology, subjectivity.

\section{INTRODUÇÃO}

Neste artigo, partimos de um tema que tem sido muito caro à psicologia social crítica, a teorização sobre o trabalho; e parece indiscutível, tanto sob o ponto de vista de uma sociologia das práticas sociais, quanto de um ponto de vista psi, afirmar que o trabalho é espaço privilegiado de constituição do sujeito, entendendo este último como resultado de processos de construção simbólica de sentido.

Os processos sempre relacionais que envolvem o trabalho, que o engendram e a partir dos quais se forjam outras relações e experiências, podem assumir configurações peculiares. Todas elas, entretanto, vão ser constitutivas da vida das coletividades que abrigam os sujeitos individuais - a consciência de si que chamamos de "eu" - e destes próprios, como alguém que age sobre o mundo para apreendê-lo. Portanto, pode-se entender muito sobre os modos de ser sujeito nas relações que engendram o trabalho, o qual assu- me características singulares com as metamorfoses trazidas pelo processo contemporâneo de reestruturação produtiva (Grisci, 2000; Antunes, 1999).

Assim, este texto ocupa-se de discutir uma experiência laboral vivenciada no campo da economia solidária, uma cooperativa urbana na cidade de Porto Alegre, Rio Grande do Sul. Esse empreendimento existiu no período de 2000 a 2003, tendo neste ultimo ano sido extinto, em meio a graves problemas institucionais. O pequeno grupo remanescente de associados iria tentar novamente empreender no campo solidário, buscando constituir uma nova cooperativa, num processo que mobilizou intensamente suas vidas e trajetórias; e este processo analisa-se aqui, com intuito de avançar na proposta de inserção da psicologia social crítica - lembrando que teorias críticas são aquelas que não concebem a realidade esgotando-se no que já existe, - no âmbito do trabalho autogestionário e solidário. 
Minha inserção nesse campo-tema (Spink, 2003) deu-se através de um vínculo inicial como pesquisadora, quando da realização do doutorado em psicologia na PUCRS. Conheci o empreendimento referido participando de uma "caravana solidária" organizada pelo gabinete da deputada estadual gaúcha Helena Bonumá, no ano de 2001 . O objetivo era visitar e conhecer vários empreendimentos de economia solidária, discutir e fomentar o trabalho nessa perspectiva. Uma vez tendo conhecido a equipe diretamente envolvida na gestão da cooperativa, me apresentei como pesquisadora e comecei os contatos para realizar as entrevistas e observações, sendo bem recebida (pesquisadores não eram, absolutamente, novidade para os participantes do empreendimento). A pesquisa que iria culminar com a defesa da tese de doutorado "A psicologia na transição paradigmática: um estudo sobre o trabalho na economia solidária" foi então sendo construída, impactada pelas vivências da pesquisadora no período. A investigação constituiu-se em um estudo de caso, análise da trajetória de um empreendimento econômico solidário, a partir do qual pode-se levantar e discutir muitas das dificuldades enfrentadas no âmbito das organizações que buscam formas alternativas de trabalhar. Neste artigo, trataremos apenas de alguns dos aspectos levantados na pesquisa, não sendo intenção esgotar completamente a riqueza dos dados levantados.

As reflexões em relação à concepção de ser humano e sua articulação com o trabalho estiveram presentes desde o início da investigação. Já nas primeiras ações sobre a natureza que nossos ancestrais empreenderam para sua sobrevivência enquanto espécie, nos re-inventamos e nos afirmamos como seres históricos que produzem saberes, práticas e especialmente sentidos, que compartilham códigos simbólicos e reinventam seu mundo. O ponto de ruptura fundamental é este salto qualitativo da natureza para a cultura que a espécie humana empreende e que determina outros elementos para mantê-la no mundo, além das forças instintuais das outras espécies, já inscritas em seu manancial filogenético. Ruptura parcial, dado que estaremos sempre ligados aos processos biológicos da vida na Terra; mas que define o humano também para além do biológico, no seu processo de constituição.

A "costura" dos elementos de sentido que formam o tecido social construído é a interação, ou mais precisamente a relação. Guareschi (2004) afirma que a palavra mais rica de possibilidades na compreensão dos fenômenos sociais é justamente a relação. E é nesse marco da sociedade produzida nas relações sociais, que o trabalho aparece como a "agulha" que costura a "linha" das matérias-primas e insumos da produção, dos serviços essenciais à vida e tudo o mais que é necessário à existência humana no planeta. Segundo Iniguéz (2003), como o sujeito produz-se através da ação e da linguagem, pode-se dizer que os instrumentos de construção da realidade são discursivos - não exclusivamente, mas em larga medida, - e é com essa matéria prima discursiva que as representações se constituem, em cima do material simbólico que os sujeitos produzem, acessam, transformam e trocam entre si através dos processos comunicacionais. O conhecimento produz-se na interpretação dos sujeitos sobre o mundo, sempre no marco cultural e lingüístico. Nesses processos complexos e não lineares, a dimensão laboral da experiência humana ocupa importante lugar. O desafio central, a partir desse referencial, era compreender como se apresentava o trabalho na perspectiva solidária e autogestionária, a partir das compreensões dos/as trabalhadores/as associados/as. É interessante definir agora alguns parâmetros dessa proposta sócio-econômica que tem sido denominada de economia solidária.

TRABALHO ASSOCIATIVO E SOLIDÁRIO: CARTOGRAFANDO, EXPERIMENTANDO E RESISTINDO

Nos últimos quinze anos, em nível de enfrentamento do problema da exclusão e em nível de políticas públicas ainda mais recentemente, surgem formas alternativas de organização do trabalho, formas mais solidárias de produzir e distribuir bens e serviços materiais e imateriais, que têm sido denominadas de economia solidária. Claro que trabalho cooperativado, autogestionado, associativo, embora incipientes sob a forma contemporânea de economia popular solidária tal como vem sendo discutida, não são conceitos novos (Singer, 2002a; 2002b).

Na verdade, os conceitos datam dos primórdios do capitalismo industrial. A primeira grande onda de cooperativismo de produção foi na Grã-Bretanha, acompanhando a luta sindical e pelo sufrágio universal. Historicamente, temos nas referências (britânica) de Robert Owen e (francesa) de Charles Fourier, os primeiros elementos que inspiraram a economia solidária, através do socialismo utópico das comunidades/associações que tentaram enfrentar, no século XIX, a precariedade social que a revolução industrial imprimira na sociedade européia, como resultado da instalação e agudização do antagonismo de classe.

As cooperativas de produção e consumo têm protagonizado alternativas às formas hegemônicas. E, no dizer de Singer (2002a), no laboratório da história, o único método disponível é o da tentativa e erro. E é justamente dessa forma que as experiências têm evoluído. Daí suas muitas dificuldades e precariedades, especialmente em países da periferia do sistema mundial, que já ocupam um lugar específico (e 
Veronese, M.V.;Guareschi, P. "Possibilidades solidárias e emancipatórias do trabalho: campo fértil para a prática da Psicologia Social Crítica"

subalterno) na divisão social do trabalho.

A palavra solidária deriva do vocábulo latino sólidu, significando força, união, adquirindo um sentido moral ao vincular-se à idéia da justiça e da união entre as pessoas para o bem comum (Mance, 1999).

É nas razões da emergência de um campo como a economia solidária que a psicologia vai buscar elementos para analisar, criticamente, a relação que os sujeitos ali estabelecem com o seu trabalho. Ao tentar produzir o conhecimento prudente para uma vida decente (Santos, 2003), encontra-se no questionamento um dispositivo importante.

Vejamos a resposta à pergunta de Razeto (1999, p. 2), "Pueden juntarse la economía y la solidaridad?" Economía de solidaridad es un concepto que si bien apareció hace pocos años está ya formando parte de la cultura latinoamericana. Cuando empezamos a usar esta expresión y en 1984 publiqué el libro Economía de solidaridad y mercado democrático, pude observar la sorpresa que provocaba asociar en una sola expresión los dos términos. Las palabras "economía" y "solidaridad", siendo habituales tanto en el lenguaje común como en el pensamiento culto, formaban parte de "discursos" separados. "Economía", inserta en un lenguaje fáctico y en un discurso científico; "solidaridad", en un lenguaje valórico y un discurso ético. Rara vez aparecían los dos términos en un mismo texto, menos aún en un solo juicio o razonamiento. Resultaba, pues, extraño verlos unidos en un mismo concepto.

Nesse sentido, na busca de uma alternativa superior à luta darwiniana pela sobrevivência, surgem possibilidades - ainda incipientes, porém muito concretas - de desenvolver um comércio justo, uma economia não-colonizadora e não patriarcal, sustentável a longo prazo.

O valor central da economia solidária é o trabalho, o saber e a criatividade humanos e não o capital-dinheiro e sua propriedade sob quaisquer formas. Sendo a referência da economia solidária cada sujeito e, ao mesmo tempo, toda a sociedade, concebida também como sujeito, a eficiência não pode limitarse aos benefícios materiais de um empreendimento, mas se define também como eficiência social, em função da qualidade de vida de seus membros e, ao mesmo tempo, de todo o ecossistema (Coraggio, 2001). O primado do valor de uso e não do valor de troca, numa linguagem marxista. A isso chamamos eficiência sistêmica, que vai além da visão instrumental de geração de lucro, na perspectiva da organização. A realização efetiva de benefícios sociais de longo prazo são essenciais para caracterizar um processo de eficiência sistêmica (Gaiger, 2003).

Andion (2001, p. 4-5) identifica também a economia solidária dentro da perspectiva da sociologia/ economia, como um conjunto de organizações que atuam no campo social, mobilizadas a partir da sociedade civil. A economia solidária, nas suas diversas formas organizacionais (cooperativas, associações, grupos informais etc), é um projeto de desenvolvimento destinado a promover as pessoas e coletividades sociais a sujeito dos meios, recursos e ferramentas de produzir e distribuir as riquezas, visando a suficiência em resposta às necessidades de todos e o desenvolvimento genuinamente sustentável. Não é uma panacéia, mas sim um projeto de organização sócio-econômica por princípios opostos ao do laissez-faire, com ênfase na cooperação em lugar da competição (Singer, 2002a; 2002b).

O objetivo do empreendimento solidário é a obtenção da quantidade e da qualidade do produto ou serviço que venha a atender a demanda social, e não apenas maximizar o lucro. O excedente terá sua destinação decidida pelos trabalhadores em assembléia, pois a propriedade e concepção coletivas dos meios e modos de gestão do trabalho deverá ser característica do empreendimento solidário, seja ele cooperativo, associativo ou comunitário. Tais critérios, obviamente, não são encontrados de forma absoluta nos empreendimentos, existindo diversos graus de apropriação dos mesmos, bem como de práticas efetivamente autogestionárias.

No Brasil, a partir das "décadas perdidas" de oitenta e noventa, houve um recrudescimento do setor, a partir da assunção de fábricas falidas pelos trabalhadores, como a Wallig no Rio Grande do Sul, a Cooperminas em Santa Catarina e a antiga fábrica de tecelagem Parahyba em São Paulo e Pernambuco. Os empreendimentos solidários hoje são contados às centenas, mais de duzentos apenas no Rio Grande do Sul.

Se os sócios têm a propriedade do negócio, devem se autogerir; portanto, as relações precisam se estabelecer em outro patamar. Essa chamada à autogestão é uma das dificuldades centrais dos trabalhadores com ela envolvidos, egressos de formas heterogestionárias, muitas vezes autoritárias, de trabalhar.

A economia solidária é também chamada de economia social e tem sido referida mundialmente como alternativa para geração de renda e como possibilidade de redefinir as relações entre economia e sociedade, no sentido de uma maior democratização da vida social (Paixão, 1998).

Como diz Gaiger (2001), diante da necessidade de resistência dos trabalhadores à dominação ca- 
pitalista, existiram para eles/as quatro alternativas: negociar a relação assalariada (lutar por melhores condições de trabalho), negar-se ao assalariamento, deixar de ser trabalhador-operário (montar seu próprio "negócio" individual), ou associar-se enquanto produtores. $\mathrm{O}$ último aspecto citado, forma de resistência já antiga, se reconfigura como a economia solidária que hoje se vincula aos movimentos sociais e à rede do movimento Fórum Social Mundial.

Segundo Guigue (2001), a economia solidária é um movimento que se esforça, depois de dois séculos, para conciliar atividade econômica e justiça social. Para Enjolras (2002), os novos paradigmas tecnológicos e informacionais integraram ainda mais o econômico ao cultural-subjetivo, de modo que, baseando-se na idéia de modernidade tardia ou reflexiva, acredita que a reflexividade estética pode abrir brechas para novos modos de ser e de viver. Isso oferece um campo de experimentação social que pode ser positivo para as práticas sociais renovadoras da economia solidária. A dimensão cultural e simbólica do capitalismo tardio é central para a economia globalizada; tem sido utilizada como forma de exploração, mas também pode abrir caminho para a experimentação.

O caráter contraditório das relações sociais na contemporaneidade abre espaços para que distintos atores sociais busquem oportunidades para o encaminhamento de suas demandas, incluindo os trabalhadores e trabalhadoras que se vêem sem possibilidades de inclusão digna no mercado de trabalho. Diante dessa realidade, o trabalho associativo e cooperativo parece ser uma das respostas viáveis, em termos de condições e meios de trabalho, ao considerar-se o empobrecimento das populações e a falta de oferta de emprego. O Programa das Nações Unidas para o Desenvolvimento (PNUD) distingue entre o crescimento favorável aos pobres (pro-poor) e o crescimento que discrimina os pobres (anti-poor). Mesmo havendo um relativo crescimento econômico, os pobres não conseguem integrar-se no processo de expansão, podendo tornar-se o trabalho veículo de precarização e não de melhoria da qualidade de vida dos que trabalham (Sachs, 2004).

A formação de redes de produção e consumo solidários acrescenta aspectos como reciprocidade e vínculos sociais fortalecidos à lógica econômica, podendo consolidar o papel da economia solidária no desenvolvimento de atividades econômicas e de geração de renda com justiça social e responsabilidade ambiental.

A força dos empreendimentos econômicos solidários (EES) reside no fato de eventualmente combinarem o espírito empresarial e o espírito solidário, unindo os vetores da autogestão/cooperação com os da eficiência/viabilidade (Gaiger, 2004; 2005). Entretanto, muitas são as dificuldades e precariedades enfrentadas, especialmente em países da periferia do sistema mundial globalizado, que já ocupam um lugar subalterno na divisão social do trabalho; e um dos pontos críticos é justamente a prática da autogestão. Nesse contexto, a pesquisa social deve revelar-se competente, pois torna-se cada vez mais evidente a relevância de se discutir o tema da autogestão e do trabalho associativo de forma crítica, contribuindo com o seu desenvolvimento. Nessa forma de organização do trabalho, as relações precisam se estabelecer em patamares de igualdade e autoridade compartilhada; torna-se vital, para os trabalhadores associados, desenvolver habilidades sociais necessárias à prática da autogestão.

Na busca de compreensão dessa realidade complexa e polimorfa, em pesquisa e produção de conhecimento, faz-se necessária a articulação de diversos campos do saber. Acredita-se que pode ser significativa a contribuição do enfoque psicossocial nos estudos sobre subjetividade, trabalho, economia solidária e autogestão. Esta pesquisa ancora-se num aporte psicossocial; para tanto, busca-se referência em estudos anteriores na análise de temas afins, nessa perspectiva. No que se refere à psicologia social, as pesquisas têm comprovado que a saúde mental, a autoestima, a vida familiar, a realização e satisfação pessoal, enfim, toda a produção subjetiva singular de cada pessoa no mundo, estão implicadas no trabalho (Jerusalinsky, 2000; Codo, 1997 e 2000; Grisci, 2000; Tittoni, 1994 e 1999; Fonseca, 2000 e 2002; Guareschi, 2004).

É de interesse para o estudo do tema do trabalho solidário, uma breve análise sócio-histórica do período atual, onde assinala-se a ressurgência da autogestão como alternativa para o trabalho explorado e mal-remunerado, ou mesmo para o desemprego.

\section{CONTEMPORANEIDADE, SUBJETIVIDADE E TRABALHO SOLIDÁRIO}

Os intelectuais da área das ciências humanas e sociais divergem quanto à nomenclatura utilizada para pensar e falar da contemporaneidade: Modernidade líquida, ou "mole" (Bauman, 2001); Modernidade tardia ou modernidade reflexiva (Beck, Guiddens \& Lash, 1994), pós-modernidade e por aí segue. Elejo o termo contemporaneidade para referir-me ao tempo presente (que inclui o passado recente), sabendo que os elementos que estão presentes nas discussões desses e de tantos outros autores fazem parte de meu entendimento sobre o tema. Fluidez - propriedade de líquidos e gases - parece a metáfora adequada para explicar a natureza da presente fase, nova sob muitos aspectos. 
Veronese, M.V.;Guareschi, P. "Possibilidades solidárias e emancipatórias do trabalho: campo fértil para a prática da Psicologia Social Crítica"

Os fluxos de capital circulam celeremente, as empresas capitalistas diminuem de tamanho (e crescem em poder), o tempo adquire uma urgência e rapidez sem precedentes, o trabalho volatiliza-se, a mídia transforma a relação das pessoas com o mundo.

Rockefeller apegava-se à suas sólidas e bem plantadas fábricas, estaleiros, propriedades que podiam durar a vida toda e além dela, muitas vidas mais; Bill Gates, entretanto, ganha dinheiro - e muda de produto - com uma velocidade quase etérea, e reciclagem é a palavra mágica no seu negócio. O sociólogo polonês Zygmunt Bauman explica como a comparação entre esses dois milionários, cada um no seu momento histórico, é paradigmática das mudanças (Bauman, 2001). Projetos custosos e compromissos (entre capital e trabalho) de longo prazo estão fora de questão. O sujeito vive como no labirinto: disperso, sem caminhos pré-definidos, procurando atabalhoadamente uma saída, e perdendo-se. Sobre o labirinto, refere que esse conceito expressa como nos vemos no mundo, hoje. Ele expressa a complexidade, a falta de clareza e das referências fixas, o sistema tortuoso. As promessas iluministas e a certeza da razão instrumental balançam e trepidam, nas convulsões que liqüefazem a sociedade contemporânea.

Parece que há um desmantelamento das ilusões modernas de que há um lugar a chegar, o qual com a firme determinação de progresso alcançaremos; de que essa sociedade melhor e ser humano aperfeiçoado ainda vão ser alcançados. Esse é o discurso da ciência moderna, que embora forte, sofre revezes constantes na contemporaneidade. A ciência e a tecnologia "justificam", através de seus agentes, empobrecimento galopante, concentração de renda, novas formas de exploração de seres humanos e da natureza. A resistência a essa configuração articula-se como pode, ou como seus agentes podem.

Portanto acredito, com Santos (2000), que o que está em jogo hoje é a disputa epistemológica entre dois paradigmas: o hegemônico (da ciência moderna, que está a ser duramente questionado) e o emergente, que consiste em experimentações na busca de modos diferentes de ser, viver e conhecer. Nessas lutas paradigmáticas, seus encontros e desencontros, o sujeito pode se perder no labirinto. Trata-se de uma transição paradigmática expressa nos níveis epistemológico e societal, ou seja, uma nova maneira de conhecer e de produzir práticas sociais, de transitar da ciência moderna para uma ciência pósmoderna, e de práticas modernas para pós-modernas - ou pós-coloniais, como o autor prefere referir hoje (Santos, 2004). Ele distingue entre o pós-moderno celebratório - niilismo, recusa da perspectiva emancipatória - daquela corrente a que se filia, o pós-moderno de oposição, o qual tem no horizonte das emancipações referência fundamental.

O campo do trabalho solidário avança, em termos societais e paradigmáticos, como um possível modo de emancipação do trabalho explorado e alienado, alternativa para os que acreditam num outro mundo possível (máxima do movimento Fórum Social Mundial), ou simplesmente precisam gerar renda em caráter emergencial.

O trabalho propicia o estabelecimento de relações onde as competências cognitivas e afetivas do sujeito são postas a prova, desenvolvidas, intensamente vivenciadas através das múltiplas experiências que o contexto laboral proporciona. É impossível dissociar, nessa perspectiva, psicogênese e sociogênese das emoções, cognições e ações de um sujeito; são processos concomitantes, e os tomamos, articulados, como processos de subjetivação.

As experiências contra-hegemônicas, em qualquer campo da experiência humana, e certamente no trabalho, são freqüentemente frágeis; acreditamos que as ciências sociais, entre elas a psicologia social crítica, têm sua parcela de contribuição a dar nesse momento histórico específico. O problema moderno da opressão, exploração e alienação está vivamente presente, embora assuma diferentes configurações na contemporaneidade. Dado o inegável fato de que o mundo contemporâneo contém muitas formas de opressão, desde formas domésticas e institucionais de violência até guerras explícitas em nome da paz, é preciso (ainda) construir, através da atividade criativa, uma ciência social preocupada com emancipação. E uma ciência responsável, antes de mais nada, que produz conhecimento prudente na busca de uma vida decente para todos (Santos, 2003).

Entender o sujeito dentro da concepção - e do projeto - de emancipação, significa, porém, pensá-lo e inscrevê-lo dentro de múltiplas possibilidades. $\mathrm{O}$ sujeito solidário, mas livre, precisa poder escolher, intersubjetivamente, dentro de seu contexto, a melhor forma de emancipar-se. Esta é uma questão ética sob o ponto de vista societal, mas também do científico; é preciso pensar, então, formas de facilitar a produção de novos processos de subjetivação, facilitadores da singularização, da criatividade e da inovação no campo do trabalho, sempre na perspectiva da eficiência sistêmica.

Para Rey (2003), a subjetividade pode ser definida como um processo complexo de construção simbólica de sentidos, sobre si e o mundo, simultaneamente um fenômeno da pessoa ou sujeito singular e de seu lugar sócio-histórico.

Conforme Guattari (1992), a subjetividade é plural, polifônica, e as origens de sua produção não podem ser analisadas nem no indivíduo, nem somente em termos infra ou supra-estruturais. Os processos 
de semiotização que estão em sua base não são dotados de fixidez, portanto vai além de categorias sociais rígidas, além de incluir aspectos etológicos e ecológicos. Opõe a massificação capitalística à singularização criativa.

O sujeito precisa de elementos lingüísticos para se representar, se constituir. A atividade representacional não pode prescindir de elementos lingüisticos. Assim, na linguagem, na ação cotidiana e na relação, produz-se o(s) sujeito(s). Produz-se a partir da concretude das experiências, da atividade que o liga ao mundo.

Muitos psicólogos ou psicólogas se preocupam com a massificação da subjetividade, a exemplo de Pelbart (2000, p. 9), que interroga-se: "De que margem de manobra dispomos nós neste final de milênio?" Também um crítico da "estratégia dita pós-moderna" (no caso, a celebratória), a qual segundo ele "deleita-se numa volúpia niilista, cultuando a dissolução generalizada, numa apologia do desfazimento e do gozo apocalíptico, basta mencionar a insistência com o tema do fim, fim do social, do político, da história, da filosofia etc.", na sua crítica instiga à busca de alternativas, o que é potencialmente transformador da realidade criticada. Percebo aqui uma convergência com a crítica de Santos (2000) ao pósmoderno celebratório. Como todo o pensador que se inquieta diante das questões contemporâneas, Pelbart conclama à resistência. A diferença desses teóricos críticos pós-modernos de oposição dos teóricos críticos modernos é que, para esses, o grito era "Façamos emergir a consciência de classe!". Para os que se arriscam hoje a teorizar e resistir, o grito não é mais unívoco, mas é pensado de formas múltiplas como a possibilidade de "(...) cartografar e resistir, apreender o que está em jogo no presente e, assim, dar visibilidade às saídas inventivas que nele se anunciam, sem nostalgias frívolas nem utopismos ortodoxos." (Pelbart, 2000, p. 10)

O sujeito, então, busca modos de empoderamento que potencializem as lutas por dignidade e direitos sociais; o campo do trabalho solidário, mesmo com todas as suas dificuldades e fragilidades, pode contudo ser campo fértil para esse processo. Assim, a questão do poder está sempre presente quando questionamos os modos de trabalhar.

\section{MODOS DE PRODUÇÃO DE PODER E TRABALHO SOLIDÁRIO}

Partindo de uma crítica a Foucault e outros autores, bem como da análise das teorias feministas ao entendimento de poder, Santos (2000, p. 248) define o poder como relacional, como "qualquer relação social regulada por uma troca desigual". Tais desigualdades, materiais e/ou imateriais, articulam-se em assimetrias de capacidades comunicativas, educativas, de tomada de decisão e de autonomia para organizar interesses, isso sem falar nas imensas desigualdades materiais que podem estar na base de tais processos. Aqui vai ficar bem clara a maneira como o autor diverge de Foucault, para quem, segundo Lazzarato e Negri (2001, p. 38), “(...) poder é a capacidade de sujeitos livres e independentes intervirem sobre a ação de outros sujeitos igualmente livres e independentes"; ou ainda, "Ação sobre uma outra ação". Em Santos, o poder é tratado como relação de troca desigual, onde a assimetria de recursos é bastante considerada. Entretanto, ambas as abordagens podem convergir para a idéia de que "(...) novas relações de poder trazem por conseqüência novos processos de subjetivação." (Lazzarato e Negri, 2001, p. 38).

Essa teorização mostra-se particularmente pertinente no caso da análise da autogestão, tema central no campo do trabalho solidário. Santos (2000) avalia que o horizonte de emancipação social que lhe instiga a trabalhar categorias sociológicas, filosóficas e psicológicas leva seu interesse a centrar-se na transformação das relações de poder existentes como dominação para a forma de relações de autoridade compartilhada. Parece-me, então, que não analisar a questão dos modos de produção de poder é deixar de fora o coração da problemática do trabalho e da subjetividade na economia solidária, com os espaços laborais que engendra e as lutas de poder que ali se travam. A fim de contextualizar a análise que procedo em seguida, apresento brevemente as concepções do autor sobre a temática.

Vejamos, na citação de Santos (2000, p. 249) como o poder se enreda nos modos de trabalhar da economia solidária, se transpusermos as fronteiras da definição:

(...) o que é mais característico das nossas sociedades é o fato de a desigualdade material estar profundamente entrelaçada com a desigualdade nãomaterial, sobretudo com a educação desigual, a desigualdade das capacidades representacionais/comunicativas e expressivas e ainda a desigualdade de oportunidades e de capacidades para organizar interesses e para participar autonomamente em processos de tomada de decisão significativa.

Portanto, faria sentido explicar através dessas assimetrias, a dificuldade que os sujeitos na economia solidária encontram para apropriar-se de novos modos de trabalhar e de se relacionar. Quem tem maior capacidade expressiva/discursiva, - dentro de uma usual concepção - pode acabar assumindo papel de "chefe", caracterizando a troca desigual. 
Veronese, M.V.;Guareschi, P. "Possibilidades solidárias e emancipatórias do trabalho: campo fértil para a prática da Psicologia Social Crítica"

As constelações de poder, complexas e contraditórias, podem fixar fronteiras - modo fixação de fronteiras, - onde irão inibir mudanças de posições e inovações relacionais entre os atores que as protagonizam. Podem ainda, e ao contrário, abrir novos caminhos modo abertura de novos caminhos, - onde permitem formas de ser diversas e partilha relativamente igualitária de capacidades. As configurações de tais modos de poder são ora expressas de um modo, ora doutro, inclusive dentro de um mesmo espaço organizacional, entre os mesmos atores. Por exemplo: um grupo de trabalhadores associados pode se unir e apoiar numa assembléia do Orçamento Participativo, para conseguir recursos; mas, ao voltar para o cotidiano de trabalho, pode prevalecer entre eles uma divisão sexual do trabalho injusta e patriarcal, onde as mulheres ficam relegadas a um segundo plano. Nesse caso, num contexto o poder foi exercido no modo de abertura; em outro, de restrição. Isso em um mesmo grupo de trabalho; como diz Santos (2000), as constelações de poder nem vagueiam ao acaso, nem são totalmente previsíveis, a exemplo do próprio sujeito.

\section{TOMANDO UM REGISTRO EMPÍRICO PARA ANÁLISE}

Voltamos agora ao registro empírico da pesquisa da qual este artigo emerge, sem que pretendase, repito, traduzir toda a sua extensão no presente texto, que visa uma reflexão inicial sobre práticas em psicologia social crítica e trabalho solidário. Um empreendimento econômico solidário, no caso uma cooperativa de distribuição de produtos variados, tendo como meta o abastecimento familiar, foi alvo de um estudo de caso.

Este método se concentra num fenômeno singular ou entidade, e intenta des-cobrir a interação de fatores significativos característicos do fenômeno. Focaliza uma descrição e explicação compreensiva. Como Yin (1984) observa, o estudo de caso é uma forma particularmente apropriada para entender condições contextuais, acreditando que elas poderão ser altamente pertinentes para o entendimento mais abrangente do fenômeno em estudo (no caso, a economia solidária). Uma unidade particular acompanhada com mais cuidado pareceu-me também fonte privilegiada de informações sobre os desdobramentos do problema da subjetividade no contexto laboral/ organizacional da economia solidária.

Ressalto que o recorte empírico utilizado neste texto corresponde apenas a um fragmento da coleta de dados da pesquisa original; mas é ilustrativo do processo vivenciado pelos trabalhadores associados e das vicissitudes que conteve a experiência, e julgo suficiente para a reflexão que aqui proponho.
A cooperativa estudada enfrentou, ao longo de dois anos e meio, muitos problemas de relacionamento interno e com os parceiros aos quais ligava-se. Os problemas ocorreram na condução do seu processo de gestão e eram de ordem financeira, administrativa e laboral, o que culminou em perda de sócios, de crédito e em graves problemas que resultaram na inviabilidade do empreendimento. Contraíram dívidas com agentes financiadores, fornecedores e demais parceiros; na época de conclusão da coleta de dados, em 2003, o grupo remanescente de associados esforçava-se no processo de encaminhar tais problemas, para recomeçar o trabalho formando outra cooperativa.

Esse grupo - aqueles que permaneceram engajou-se num processo de reflexão sobre seus erros e acertos e reavaliação crítica de toda a trajetória vivenciada, tentando reerguer-se e recomeçar o trabalho. Buscavam constituir uma nova cooperativa mista de trabalho, produção e consumo ético. Reproduzo, para ilustrar melhor o processo vivenciado, alguns trechos dos diálogos entre os participantes da pesquisa e uma figura-esquema da sua trajetória. Esse esquema descreve as etapas do processo grupal vivenciado, ilustrando-as com falas dos participantes.

Os diálogos transcritos abaixo tiveram lugar em uma reunião dos sócios remanescentes da cooperativa original, com parceiros das ONG's de apoio, pesquisadora, representante da prefeitura municipal e antigos sócios, na busca de apoio e idéias, bem como de novos sócios para a cooperativa que queriam (re)criar.

Diálogos:

"C- Houve mais dificuldades que acertos no nosso caso!

$\mathrm{CH}$ - O projeto era bom, o grande problema foi o despreparo da gente como coordenação, como cooperativa; a gente não tinha experiência, tudo era novo pra nós. A gente se dividiu, o coordenador era a pessoa que mais entendia da parte legal, e a gente confiou, mas ele foi sem sorte na coordenação..., assina isso, assina aquilo, os sócios sem saber direito o que era... A grande verdade é que a culpa é de todos... Eram três coordenadores gerais... todos se omitiram igual... $K$ - (Interrompendo) Queremos recomeçar, fazer uma cooperativa de verdade, autogestionária e democrática. Desta vez, não cometeremos os mesmos erros. Quando pudermos, sanearemos as dívidas. A gente tem nosso fogão industrial, geladeira, um computador... ganhamos um 
caminhão no valor de $R \$ 30.000,00$ no Orçamento Participativo, mas não podemos retirar pois não temos a negativa de dívidas com a Prefeitura. Mas a gente pode se reerguer, se pegar todo o mundo junto, lutando pelo projeto do consumo ético e de uma sociedade melhor.

Cc- Não sei se o melhor é necessariamente formar outra cooperativa, vocês têm outras opções: micro-empresa, sociedade... C- Mas nós acreditamos no cooperativismo, na economia solidária, será que queremos voltar pro sistema capitalista?

Cc- Olha, o objetivo é a recuperação do empreendimento, a gente sabe que os princípios norteadores são solidários, mas tem muitas formas de se constituir. $K$ - É isto mesmo, é isso aí, se todos os companheiros aqui derem opiniões, a gente chega lá, busca um consenso e vai embora de novo. Só que dessa vez, com total transparência entre os sócios.

Figura 1: Esquema da trajetória dos participantes do empreendimento

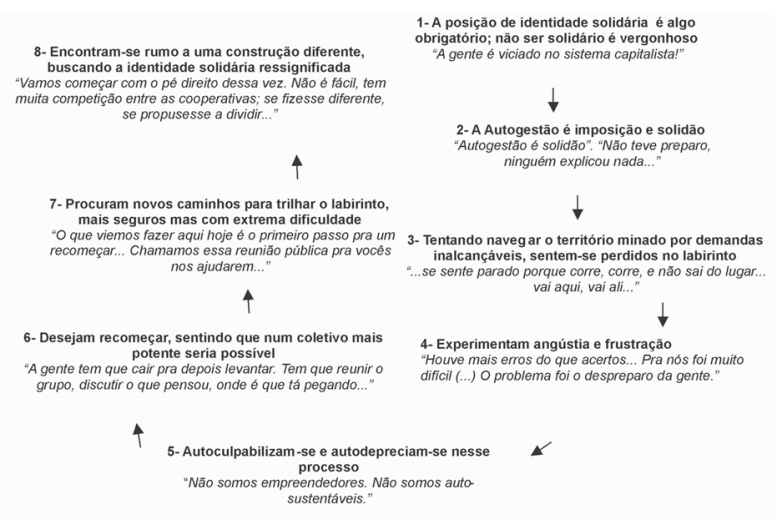

O esquema reconstrói as dificuldades de constituir uma cooperativa dentro dos parâmetros e valores solidários, que apresentam-se para os participantes do empreendimento através dos discursos/saberes que circulam no campo. Essas zonas de sentido incluem uma forte expectativa de transformação e superação, identificação dos projetos da economia solidária com uma sociedade melhor e mais justa, um novo mundo possível a ser construído. E vivenciam a frustração de ver que, na prática, não foi bem assim, pelo menos neste caso.

São idealizadas, pelos atores da economia solidária, formas de se relacionar, sentir e agir; é como se essa posição de identidade solidária fosse algo obrigatório para eles. Eles precisam pedir (a si mesmos, a mim, a todos) muitas desculpas por não conseguirem efetivar tal posição, por não poderem impedir a vivência das relações de poder como fixadoras de fronteiras. Culpabilizam-se por não terem tido a competência necessária para a prática da autogestão; referem que comportar-se como capitalista, pegar os vícios do capitalismo, é algo vergonhoso para sócios de um empreendimento cooperativo e solidário.

Pode-se argumentar que as duas dimensões da transição paradigmática - a epistemológica e a societal, - interligadas e interdependentes, estão presentes nos conflitos enfrentados pelos participantes. Percebe-se a competição entre um paradigma emergente (o solidário), que tenta impor-se, e um paradigma anterior (o capitalístico) que insiste em corporificar-se nas relações de trabalho. Materializase por constituir a "geografia" já conhecida dos sujeitos narradores, por serem eles mesmos fruto daquele modo de subjetivação.

O modo de subjetivação capitalista do paradigma ainda hegemônico, caracterizado pela concentração de poder, pela postura de espectador dos trabalhadores, impõe suas maneiras de trabalhar; ao tentarem, intuitivamente, propiciar as trocas de conhecimento dentro da experiência de desenvolvimento, trabalho e produção que empreendiam, os participantes "perderam-se" num labirinto cujo mapa, a princípio, ninguém tinha. As trocas igualitárias entre os diferentes conhecimentos seriam talvez as responsáveis pelo processo coletivo de traçar possíveis mapas de trânsito no labirinto. Este último, metáfora para as perplexidades daqueles que tentam navegar nas águas do "capitalismo leve e fluido" (Bauman, 2001), exige uma instantaneidade de aprendizados e atos que o tempo singular dos sujeitos que precisam aprender a enfrentá-lo não alcança, não sendo ele da ordem do instantâneo.

As zonas de sentido podem configurar-se contraditórias, assustadoras. Ao perceberem-se no labirinto, sem as ferramentas necessárias para enfrentálo, os cooperativados sofrem. Os minotauros - nessa versão do labirinto eles são muitos, e possuem variadas formas - espreitam, prontos a impedirem-lhes o acesso a uma renda digna e um trabalho satisfatório e solidário.

O labirinto é geométrico, mas o é de uma forma absolutamente incompreensível; além do que, a cada passo, existe a possibilidade do Minotauro, o pesadelo do fracasso. Não se conhecem todas as passagens do labirinto, como não se conhecem todas as passagens da vida. A perplexidade une-se à solidão, já que ninguém parece oferecer o fio de Ariadne que poderia conduzir à saída do labirinto. 
Veronese, M.V.;Guareschi, P. "Possibilidades solidárias e emancipatórias do trabalho: campo fértil para a prática da

Psicologia Social Crítica"

Sob o ponto de vista psicológico, as desigualdades de recursos são percebidas com sofrimento, especialmente por parte daqueles que possuem baixo nível de educação formal. As competências do "eu" são percebidas como limitadas e inadequadas na esfera pública laboral, estando presente a autoculpabilização pelas falhas no processo. A percepção de si como inferior e incapaz acaba dando margem às desistências de ser sujeito da gestão do empreendimento e de produzir a gestão compartilhada, ou autogestão. O sofrimento que acompanha a suposta incapacidade e esse sentimento de inadequação, provavelmente está ligado à constante interpelação que é feita no sentido da autogestão, do domínio de si na relação com a alteridade e no espaço do trabalho solidário.

Apesar das dificuldades enfrentadas, alguns trabalhadores e trabalhadoras propuseram o recomeço, buscando relacionar-se entre si e com a comunidade no modo abertura-de-novos-caminhos, resistindo, cartografando e experimentando um novo rumo nesse labirinto intrigante e por vezes desesperador da vida cotidiana na contemporaneidade.

\section{PAPÉIS POSSÍVEIS PARA A PSICOLOGIA SOCIAL CRÍTICA NESSE CONTEXTO}

Ao inserir-se no espaço-tempo engendrado pelo trabalho solidário, a psicologia pode ter um laboratório importante de análise da transição paradigmática em curso. É importante, então, a pesquisa em psicologia nesses novos meios de produzir, apropriarse e dividir o produto final do trabalho, visando contribuir nos processos em que racionalidades diversas das tradicionais ou hegemônicas irão expressar-se e desenvolver-se.

Esse processo é aberto, complexo, sem verdades definitivas. É um laboratório vivencial de toda a sociedade, que precisaria, talvez mais do que nunca, formar comunidades interpretativas (Santos, 1996; 2000); comunidades essas que traçassem, conjuntamente, mapas para enfrentar o labirinto. Cartografar, se não a saída do labirinto - nem sabemos se há saída, - a possibilidade de nele movimentar-se sem tanto sofrimento, acabando por, quem sabe, conseguir subvertê-lo de algum modo, criando alternativas coletivas para seu enfrentamento.

A psicologia social crítica do trabalho poderia ocupar-se de participar, através de seus agentes (pesquisadores/as, psicólogos/as, estagiários/as), das transformações da subjetividade, na micro-política das relações laborais. Contribuir para transmutar relações de poder autoritárias em relações de autoridade compartilhada, através de práticas dialógicas; a idéia regulatória presente nessas práticas, segundo Santos (2003) é o socialismo como democracia-sem-fim, mas no caso a micro-política da democracia-sem-fim nas relações.

Seria importante que as pessoas pudessem participar dos processos que organizam os recursos para fazer funcionar o empreendimento, apropriando-se de formas mais autônomas de produzir a gestão, através de uma racionalidade própria aos empreendimentos solidários. Tal racionalidade assenta na comunidade de trabalho (Gaiger, 2005), a qual funda-se em vínculos de reciprocidade, que diluem as eventualmente rígidas fronteiras entre interesses individuais e coletivos. Também é apontado, como um fator positivo, a indivisão social entre capital e trabalho, característica dos EES. Quem trabalha, deverá apropriar-se do produto final deste trabalho, além de participar da sua gestão e organização. Isso precisa ser garantido pelos mecanismos institucionais da gestão do empreendimento, para que sua forma de racionalidade demarque-se como solidária e justa, implicando novos processos de subjetivação com sentido emancipatório.

A psicologia social crítica do trabalho pode ocupar-se de discutir e problematizar as transformações da subjetividade na autogestão, no âmbito da micro-política das relações laborais, ou seja, nos encontros, assembléias, reuniões, seminários, espaços de formação profissional etc. As práticas dialógicas podem efetivar-se em programas de educação para a autogestão, por exemplo - parte importante dos processos de incubagem de empreendimentos, - ou de aprendizagem cooperativa. Esta última, referida como processo-chave para o sucesso dos empreendimentos econômicos solidários (Schneider, 1999), pode facilitar uma apropriação mais rica dos saberes necessários à autogestão.

Na ausência de diálogo, de condições relativamente igualitárias de conversação, de relações de autoridade compartilhada, como avaliar se as fontes de recursos e de formação são adequadas? Torna-se relevante construir modelos metodológicos abertos, intrinsecamente dialógicos, que possibilitem a clara expressão das dificuldades, visando identificar, avaliar e valorizar as especificidades das empresas da economia popular e solidária, no registro coletivo do empreendimento e para cada participante individualmente.

A aprendizagem cooperativa é uma metodologia de trabalho em grupo que transforma a heterogeneidade em um elemento que facilita e incentiva o aprendizado (Monereo e Gisbert, 2005). Simulando situações que devem ser resolvidas em colaboração, os aprendizes vivenciam a interação positiva - mesmo que eventualmente conflituada, - com colegas e aprendem a se expor, argumentar e ouvir. Estimular sentimentos recíprocos de ajuda faz parte da intervenção, como prática pedagógica (busca de 
novos esquemas cognitivos) e como prática psi (busca de novos processos de subjetivação). É preciso construir uma relação onde o sucesso de cada membro está ligado à conquista do grupo, potencializando o coletivo, gerando uma postura reflexiva e crítica.

Nessas comunidades de trabalho, autointerpretativas e autocríticas, o senso comum emancipatório teria de ser produzido intersubjetivamente. Sua construção comportaria três dimensões: A dimensão ética (solidariedade) a dimensão política (participação) e a dimensão estética (prazer/erotização, autoria individual, reconhecimento) (Santos, 2000). As duas primeiras dimensões são autoexplicativas: já estão corporificadas nos consensos que orientam o campo da economia solidária. A terceira dimensão convida ao reencantamento do mundo, no sentido de um senso comum reencantado. O reencantamento com o mundo é a possibilidade de ter prazer, de erotizar as experiências, de encantar-se com aquilo que produziu. É um grande desafio, especialmente nas duras e adversas condições materiais da periferia do sistema-mundo como é o caso do Brasil.

Para tanto, a psicologia social crítica do trabalho deverá revelar-se criativa, apreendendo junto com os atores do campo possibilidades de erotização, através do reconhecimento da autoria individual e coletiva no trabalho, bem como da potencialização de relações de trabalho mais satisfatórias.

As articulações com outras disciplinas fazemse necessárias e profícuas; a educação cooperativa é um exemplo claro disto, podendo incorporar contribuições de diversas áreas disciplinares (Monereo e Gisbert, 2005). Sugere-se o trabalho em grupos - oficinas, vivências, seminários, encontros, reuniões para discussão, - viabilizando a troca complementar entre os agentes dos EES, abordando temas como: consumo ético, produção associativa, organização do trabalho, comércio justo, diálogos interculturais etc. Divulgar/ popularizar esses temas, pode ser prática cotidiana incorporada ao saber/fazer psicológico.

Essas são tentativas concretas de responder coletiva e criativamente às necessidades criadas pela globalização neoliberal, podendo significar a tradução do sentimento de que a construção de um outro mundo é efetivamente possível e significa mais um passo na direção do "conhecimento prudente para a vida decente" (Santos, 2004).

\section{REFERÊNCIAS}

Albuquerque, Paulo Peixoto. (2003). Autogestão. In Cattani, Antonio David. (Org). A outra economia (pp. 20-25). Porto Alegre: Veraz Editores.

Andion, Carolina. (2001). As Particularidades da Ges- tão em Organizações da Economia Solidária. Trabalho apresentado no XXV ENANPAD, Campinas.

Antunes, Ricardo. (1999). Os sentidos do trabalho: Ensaio sobre a afirmação e a negação do trabalho. São Paulo: Boitempo Editorial.

Bauman, Zygmunt. (2001). Modernidade líquida. Rio de Janeiro: Jorge Zahar.

Beck, Ulrich; Guiddens, Anthony; LASH, Scott. (1994). Reflexive modernization: Politics, tradition and aesthetics in the modern social order. Cambridge: Politic Press.

Codo, Wanderley (1997). Um diagnóstico do trabalho. In Tamayo, A. (Org.) Trabalho, Organizações e Cultura (pp. 21-40). Coletâneas da ANPEPP. São Paulo: Cooperativa de Autores Associados.

Codo, W. (2000). Educação, carinho e trabalho. Petrópolis: Vozes.

Coraggio, Jose Luiz. (2001). Problematizando la economía solidaria y la globalización alternativa. Presentación en el II Encuentro Internacional sobre Globalización de la Solidaridad. Disponível em: $<$ http://www.fronesis.org >

Eenjolras, Bernard. (2002). L'economie solidaire et le marché: modernité, société civile et démocratie. Paris: Éditions L'Harmattan.

Fonseca, Tania Mara Galli. (2000). Gênero, subjetividade e trabalho. Petrópolis: Vozes.

Fonseca, Tania Mara Galli. (2002). Modos de trabalhar, modos de subjetivar em tempos de reestruturação produtiva. In Fonseca, T. M. G. (Org.) Modos de trabalhar, modos de subjetivar em tempos de reestruturação produtiva: um estudo de caso (pp. 1328). Porto Alegre: Ed. UFRGS.

Gaiger, Luiz Inácio. (1999). O trabalho ao centro da economia popular solidária. Trabalho apresentado no XXIII Encontro anual da ANPOCS, Caxambú.

Gaiger, Luiz Inácio. (2001). Economia popular solidária: uma conversa de Luiz Inácio Gaiger com o Conselho de Escolas de Trabalhadores. Rio de Janeiro: NOVA Pesquisa e Assessoria em Educação, 2001.

Gaiger, Luiz Inácio. (2003). Eficiência sistêmica. In Cattani, Antonio David. (Org). A outra economia (pp. 125-129). Porto Alegre: Veraz Editores. 
Veronese, M.V.;Guareschi, P. "Possibilidades solidárias e emancipatórias do trabalho: campo fértil para a prática da Psicologia Social Crítica"

Gaiger, Luiz Inácio. (2004). As emancipações no presente e no futuro. In Gaiger, Luiz Inácio (org.). Sentidos e experiências da economia solidária no Brasil. Porto Alegre: Editora UFRGS.

Gaiger, Luiz Inácio. (2005). A racionalidade dos formatos produtivos autogestionários. Trabalho apresentado no XII Congresso Brasileiro de Sociologia, Belo Horizonte.

Grisci, Carmem Ligia Iochins. (2000). Trabalho, tempo e subjetividade: a reestruturação do trabalho bancário. Tese de doutorado em Psicologia. Pontifícia Universidade Católica do Rio Grande do Sul, Porto Alegre, Brasil.

Guareschi, Pedrinho Arcides. (2004). Psicologia social crítica. Porto Alegre: Mundo Jovem.

Guattari, Felix. (1992). CAOSMOSE: um novo paradigma estético. Rio de Janeiro: Editora 34.

Guigue, Bruno. (2001). L'economie solidaire: alternative ou paliatif? Paris: Éditions L'Harmattan.

Iniguéz, Lupicínio. (2003). La psicologia social en la encrucijada postconstrucionista. Identidad, subjetivacion, preformatividad, red, multiplicidad, acción. Conferência de abertura do XII Encontro Nacional da ABRAPSO: Estratégias de construção do presente - a Psicologia Social no contemporâneo. Pontifícia Universidade Católica do Rio Grande do Sul, Porto Alegre, Brasil, 14-17 de outubro.

Jerusalinski, Alfredo. (2000). O valor simbólico do trabalho e o sujeito contemporâneo. Porto Alegre: Artes e Ofícios.

Lazzarato, Maurizio; Negri, Antonio. (2001). Trabatho imaterial: formas de vida e produção de subjetividade. Rio de Janeiro: D\&PA.

Mance, Euclides. (1999). A revolução das redes. Petrópolis: Vozes.

Monereo, Carles; Gisbert, David Duran. (2005). Procedimentos para a aprendizagem cooperativa. Porto Alegre: Artmed.

Paixão, Marcelo. (1998). Economia Social e criação de emprego. Lisboa: Ministério do trabalho e solidariedade.

Pelbart, Peter Pal. Prefácio. In FONSECA, Tania Galli. e Francisco, Deise. (2000). Formas de ser e habitar a contemporaneidade (pp. 9-11). Porto Alegre: Editora da Universidade.

Razzeto, Luis. (1999). Economia Solidária? Persona y Sociedad 13, (pp. 2-12).

Rey, Fernando Gonzalez. (2003). Sujeito e subjetividade. São Paulo: Thomson.

Sachs, Ignacy. (2004). Trabalho decente: Ponte entre o "econômico" e o "social". Disponível em: <http:// www.ilo.org/public/portugue/region/ampro/brasilia/ hst_pgemp/downloads/sachs_td_ponte.doc.>, Acessado em 10 de março.

Santos, Boaventura de Sousa. (1996). Pela mão de Alice: o social e o político na pós-modernidade. São Paulo: Cortez.

Santos, Boaventura de Sousa. (2000) A crítica da razão indolente. Contra o desperdício da experiência. Porto: Afrontamento.

Santos, Boaventura de Sousa. (2003). Conhecimento Prudente para uma Vida Decente: um discurso sobre as ciências revisitado. Porto: Afrontamento.

Santos, Boaventura de Sousa. (2004). Do pós-moderno ao pós-colonial e para além de um e de outro. Conferência de abertura do VIII Congresso Luso-AfroBrasileiro de Ciências Sociais. Coimbra, 16-18 de setembro.

Schneider, José Odelso. (1999) Democracia, participação e autonomia cooperativa. 2. ed. São Leopoldo: Unisinos.

Singer, Paul. (2001) Globalização e desemprego: diagnóstico e alternativas. São Paulo: Contexto.

Singer, Paul. (2002a ). Introdução à economia solidária._São Paulo: Fundação Perseu Abramo.

Singer, Paul. (2002b). A recente ressurreição da Economia Solidária no Brasil (pp. 81-103). In Santos, B. (Org) Produzir para viver: os caminhos da produção não-capitalista. Rio de Janeiro: Civilização brasileira.

Spink, Peter. (2003) Pesquisa de campo em psicologia social: uma perspectiva pós-construcionista. Psicologia e sociedade. 15 (2) (pp. 18-23).

Tittoni, Jaqueline. (1994). Subjetividade e trabalho. Porto Alegre: Ortiz. 
Tittoni, Jaqueline. (1999). Trabalho e sujeição: trajetórias e experiências de trabalhadores demitidos no setor petroquímico. Tese de doutorado em sociologia. Universidade Federal do Rio Grande do Sul, Porto Alegre, Brasil.

Yin, R. (1984). Case study research: design and methods. Newbury Park: Sage.

Marília Veríssimo Veronese. Mestre e Doutora em Psicologia pela PUCRS. Docente e Pesquisadora do Programa de Pós-

Graduação em Ciências Sociais Aplicadas da UNISINOS.

Av. Unisinos, 950 - Bairro Cristo Rei CEP 93022-000 - São Leopoldo - RS - Brasil Os e-mails da autora são: mariliav@unisinos.br/mariliavero@yahoo.com.br

Pedrinho Guareschi. Mestre em psicologia social pela Marquette University (EUA). Doutor em sociologia e comunicação pela Universidade de Wisconsin. Pósdoutor em sociologia pelas Universidades de Wisconsin e Cambridge. Docente e pesquisador do Programa de Pós-Graduação em Psicologia da

PUCRS. Pesquisador do CNPq. Instituto de Psicologia Campus Universitário Central Av. Ipiranga, 6681 - Partenon - CEP 90619-900 Porto Alegre - RS - Brasil

O e-mail do autor é: pguares@pucrs.br

Este artigo tem origem na pesquisa desenvolvida pela primeira autora no doutorado em psicologia da PUCRS, sob orientação do Prof. Dr. Pedrinho Guareschi e co-orientação em regime de bolsa sandwich com o Prof. Dr. Boaventura Sousa Santos (Universidade de Coimbra). Para o doutorado, o apoio foi da Capes; para o sandwich, o apoio foi do CNPq.

\section{Marília Veríssimo Veronese e \\ Pedrinho Guareschi \\ Possibilidades Solidárias e Emancipatórias \\ do Trabalho: campo fértil para a prática da \\ Psicologia Social Crítica}

Recebido: 17/03/2005

$1^{\text {a }}$ revisão: 13/06/2005

Aceite final: 28/06/2005 